\title{
HISTÓRIA DOS HOMENS NO BRASIL
}

\author{
History of men in Brazil
}

Antonio Fontoura Jr.

PRIORE, Mary del; AMANTINO, Marcia (orgs.) História dos homens no Brasil. São Paulo: Editora UNESP, 2013. 415p.

Se durante muito tempo o "homem" foi o ser universal e senhor da história (assim, pelo menos, boa parte da historiografia fazia crer), o conjunto de artigos que compõe "História dos homens no Brasil" afirma desejar entender os homens, em sua pluralidade, enquanto seres sexuados e historicamente constituídos.A obra objetiva levantardiscussões sobre as masculinidades em seus vários papéis - pais, padres, escravos, soldados - em suas específicas diferenças, dominações e submissões, controles e virilidades.

Lançada em 2013, e organizadapor Mary del Priore e Márcia Amantino, ambas professoras da Universidade Salgado de Oliveira de Niterói,a obra é composta por 12 artigos, cujos temas partem do período colonial até alcançar os lutadores de MMA da atualidade, e objetivaapresentar um quadro amplo a respeito dos recentes estudos sobrea construção das masculinidades no Brasil.

No capítulo que abre o livro - "Ser homem... ser escravo" - Marcia Amantino e Jonis Freire discutem comoa grande superioridade numérica masculina na escravaria do Brasil, resultado da maior rentabilidade obtida com o comérciopara escravos homens, impactou o período colonial.O desequilíbrio existente entre o número

* Doutorando do Curso de Pós-Graduação em História da Universidade Federal do Paraná. Bolsista do CNPq. 
de homens e mulheres cativos terá consequências para a construção das masculinidades: os escravos buscarão construir uniões com mulheres indígenas; participarão mais frequentemente de práticas sexuais não socialmente sancionadas (como a homossexualidade) em comparação com escravas; serão superiores em número como fugitivos e, também, como habitantes em quilombos.

No segundo capítulo ("Entre homens e anjos: padres e celibato no período colonial no Brasil"), Robert Daibert Jr. busca demonstrar que a construção de um ideal celibatário para os padresum autocontrole sexual que os tornaria moralmente superiores aos leigos, segundo a Igreja -,reforçado no Concílio de Trento, foi implementado com muita dificuldade entre os religiosos que atuavam no Brasil do período colonial. Dentro de um contexto em que a própria Igreja se mostrava vacilanteem sua defesa do celibato,os religiosos oscilavam entra a castidade e a participação em práticas sexuais diversas, fossem homo ou heterossexuais, passageiras ou estáveis. A possibilidade de manejar um poder sagrado, alémdo prestígio social que possuíam, foramfrequentemente utilizados na busca pela satisfação de suas vontades eróticas. Será apenas a partir do século XVIII que a Igreja católica procurará reforçar, no Brasil, os ideais celibatários dos religiosos.

O textode Eduardo Schnoor - "Riscando o chão: masculinidade e mundo rural entre a Colônia e o Império", capítulo 3 -reproduz excertos de um processo de herança e reconhecimento de paternidade aberto em Vila de Areias (Rio de Janeiro), 1830. O capítulo trata mais de questões empíricas do que teóricas, nãoapresentando maiores discussões em torno do tema masculinidade.

No capítulo 4, Victor Andrade de Melo discute como as atividades esportivas participavam, no Brasil do século XIX, do processo de construção de uma nacionalidade ("Novas performances masculinas: o esporte, a ginástica, a educação física”). Em um período relativamente conturbado nas relações do Brasil com países 
vizinhos, havia uma preocupação social em construir, inclusive com o auxílioda medicina, um tipo de cidadão fisicamente forte, capaz de cumprir com suas obrigações sociais e, se fosse o caso, defender a pátria: um cidadão soldado. Neste contexto, atividades corporais como dança, turfe, ginástica e natação, construíam masculinidades,além de moldarem corpos em direção a este ideal. Visualmente expostos e fisicamente exigidos, os corpos realizavam performances que permitiriam tanto a diferenciação em relação às mulheres, que se adequavam a um papel de espectadoras, quanto dos homens entre si.

No quinto capítulo - "Pais de ontem: transformações da paternidade no século XIX" -, Mary del Priore analisa o processo de mudança de uma autoridade paterna autoritária e exercida aos gritos, característicasdo período colonial, para uma relação marcada pelo afeto no final do século XIX: "passava-se do pai tirano ao pai amoroso" (p. 174).Enquanto o pai colonial, símbolo do poder e elo entre o Estado e a família, estava preocupado com a sobrevivência, manutenção de laços de sangue e continuidade de linhagem, no século XIX ele se tornará o protetor familiar, e figura pela qual se desenvolverá um apego voluntário. Uma transformação queterá suas próprias disputas, pois o aumento da longevidade do pai conflitará com a presença cada vez maior dos filhos na vida pública. A urbanização fazia declinar o prestígio do patriarca e, mesmo, o respeito à velhice.O "senhor pai" temível de outrora, passará a ser o "papai”, o "papaizinho". Ainda assim, consolida-se a figura do pai que cuida de sua família e ama seus filhos, em um pensamento reforçado pelo higienismo do final do século, quando será também considerado fundamental para a formação do "bom cidadão".

No capítulo 6, de Márcia Pinna Raspanti - “O que eles vestem: moda, vaidade e masculinidade no Brasil" -, a roupa é vista por ela mesma, sem relação com a sociedade em que se insere.O capítulo apresenta um grande recorte temporal, do período colonial a meados do século XX, o que propicia generalizações e, além disso, 
apresenta uma abordagem mais descritiva do que analítica da questão davestimenta masculina.

No capítulo 7, Antonio Emilio Morga procura demonstrar o conflituoso processo de mudanças de sociabilidades existente durante o Segundo Reinado ("Masculinidade em Nossa Senhora do Desterro e Manaós: territórios e ardis"), através de um paralelo entre as realidades de Nossa Senhora do Desterro em Santa Catarina, e Manaus, no Amazonas. Seu objetivo é discutir como ocorreu um determinado processo civilizadornestas regiões, reflexo tanto das mudanças do capitalismo internacional como das novas abordagens sobre o urbano (p. 228).O artigo, que se centra na construção das sensibilidades burguesas locais e sua busca em modificar os costumes tradicionais das populaçõesem direção ao que acreditavam ser moderno, aborda de forma apenas marginal a específica questão das masculinidades.

No capítulo 8, "Masculinidade e virilidade entre a Belle Époque e a República”, DeniseBernuzzi de Sant'Anna discute o processo de constituição de novos padrões de masculinidade no Brasilque surgiam nas cidades e que se diferenciavam de ummodelo rural de valentia e força. Não que estas característicastivessem desaparecido,mas modificavam-se, diante de uma nova realidade. Em uma urbanidade crescente, a força esportiva começava a ser um diferencial entre os homens; e a coragem, por sua vez, ligava-se também ao domínio das máquinas - como do automóvel, um dos símbolos da modernidade. Crescer e se desenvolver neste espaço urbano exigiaa construção de uma visibilidade e, por isso, a aparência tornava-se, cada vez mais, parâmetro de julgamento. Cuidados com a barba, preocupação com a calvície, e em manter a aparência jovem eram explorados nas revistas e refletiam uma crescente preocupação masculina. Neste período de mudanças, cumprir com estas expectativasexigia esforço, crescimento, superação, competição - demandas contínuas para queos homens pudessem reafirmar para si, bem como assegurar perante aos outros, a própria masculinidade. 
Vitor Izecksohn, no capítulo 9, demonstra como a participação militartendeu a ser vistacom temor e repulsa, durante boa parte da história do Brasil. Em "Quando era perigoso ser homem. Recrutamento compulsório, condição masculina e classificação social no Brasil" são abordadas as várias maneiras pelas quais, nos períodos colonial, Imperial, e Republicano, respectivamente, buscou-se resolver o problema da necessidade de Forças Armadas regulares. Ser soldado foi considerado, até a República, uma tarefa especialmente abjeta: o recrutamento forçado desestruturava famílias, expunha os homens aos perigos não apenas das batalhas, mas também das doenças nas péssimas condições de saúde dos acampamentos, e era visto em síntese como injusto. Foi por decorrência das expressivas perdas humanas e materiais enfrentadas com a Guerra do Paraguai, que o exército brasileiro iniciou um processo de mudança. O recrutamento, que passou a ser por sorteio a partir de 1916 (implementando uma lei aprovada oito anos antes), foi melhor aceito pela população e a própria imagem da instituição militar foi reformada, vinculando-aa uma oportunidade de mobilidade social para a população pobre, além deuma atuação patriótica junto à República.

No capítulo 10, Angélica Müller procura traçar um amplo quadro das modificações pelas quais o conceito de virilidade passou durante o que a autora chama de "tempo de 68". Em "Não se nasce viril, torna-se: juventude e virilidade nos 'anos 1968" a autora buscaapenas "listar questões pertinentes" (p. 333) sobre como a ideia de "viril" foi herdada e reinterpretada pela juventude de 1968, argumentando que os ideais de rebeldia chegavam estilizados pelo mercado e pela cultura pop. Os discursos sobre a masculinidade, embora acompanhados de ideais libertários, não se afastavam sensivelmente das concepçõesmais tradicionais.E mesmo grupos de extrema esquerda, que se viam como revolucionários, reproduziam papéis sociais de gênero constituídos. 
Marko Monteirodemonstra, no capítulo 11 ("Masculinidades em revista: 1960-1990"), que os questionamentos ao modelo tradicional de masculinidade trouxeram mudanças nos papéis de gênero, mas que estas não foram tão simples, e nem caminharam necessária e facilmente em direção a um respeito a diferentes masculinidades. A partir da análise do conteúdo de revistas Ele Ela, Vip Exame e Sui Generis, Monteiro afirma que desde o final dos anos 60, o questionamento aos papéis sociais de gênero foi acompanhado de uma crítica ao feminismo, e por um receio de mudanças que pudessem contrariar o que seria uma "verdadeira" masculinidade. Ainda nos anos 1980 e 90, concepções tradicionais continuariam a ser defendidas. A Vip Exame, por exemplo, apresentava a ideia de um homem moderno que era sempre heterossexual, e todas as concessões à feminização - como gosto por roupas ou produtos de beleza - seriam justificadas pelo desejo que poderiam despertar nas mulheres. Já a Sui Generis apresenta o homem homossexual, leitor preferencial da revista, sempre másculo, e cuja legitimidade viria de sua participação no consumo.

A partir de entrevistas realizadas com atletas, a psicanalista Joana de Vilhena Novaes analisa, no $12^{\circ}$ e último capitulo- "“Aqui tem homem de verdade'. Violência, força e virilidade nas arenas de MMA" -,as relações entre virilidade e violência nas academias de MMA (Mixed Martial Arts). Estes atletas, a partir de sua intensa relação com as lutas e as academias, construíram uma identidade e um capital simbólico que reforçam a relação entre masculinidade, virilidade e violência - um tipo de relação ainda presente em nossa cultura. Ao se considerarem bons provedores, pais de família, pessoas religiosas, estes lutadores conformam uma imagem conservadora dos papéis de gênero que atrai, por sua vez, mulheres que compartilham semelhantes visões e que acreditamna relação "sedução viril vs. fraqueza feminina".

O título escolhido para a obra - "História dos homens no Brasil" - evoca o que seria o uso do conceito de gênero enquanto 
uma categoria analítica, com foco nas masculinidades, para análise de vários momentos da história do país: noção reforçada pelo esforço em apresentar artigos que tratam desde o período colonial à contemporaneidade. A obra, no entanto, é irregular, com alguns bons artigos acompanhados por outros que tratam seus temas de maneira meramente descritiva, além de pouco fundamentados teoricamente.

E ainda que seja um passo adiante no estudo das masculinidades - afinal, é resultado de um aumento do interesse neste campo de pesquisas, ainda mais destacado com a recente publicação da coleção "História da Virilidade" no país -, a obra apresenta problemas que são semelhantes a outras que, como essa, buscam apresentar grandes sínteses a partir de extensos recortes temporais: perde-se a densidade da discussão das temáticas propostas e criam-se análises generalizantes, que não condizem com as tendências historiográficas mais recentes.

Recebido em 5 de março de 2014

Aprovado em 30 de setembro de 2015

1 CORBIN, Alain; COURTINE, Jean-Jacques; VIGARELLO, Georges (orgs.). História da virilidade (3 vols.). Petrópolis (RJ): Vozes, 2013. 